\title{
Orbit
}

The International Journal on Orbital Disorders, Oculoplastic and Lacrimal Surgery

ISSN: (Print) (Online) Journal homepage: https://www.tandfonline.com/loi/iorb20

\section{Cellular angiofibroma of the orbit}

\author{
G.J. Hötte , R.M. Verdijk , M. Gardeniers \& D. Paridaens
}

To cite this article: G.J. Hötte , R.M. Verdijk , M. Gardeniers \& D. Paridaens (2020): Cellular angiofibroma of the orbit, Orbit, DOI: $10.1080 / 01676830.2020 .1782443$

To link to this article: https://doi.org/10.1080/01676830.2020.1782443

曲 Published online: 23 Jun 2020.

Submit your article to this journal

Џ Article views: 12

Q View related articles $ᄃ$

View Crossmark data \lceil 


\title{
Cellular angiofibroma of the orbit
}

\author{
G.J. Hötte ${ }^{a}$, R.M. Verdijk ${ }^{a, b}$, M. Gardeniers ${ }^{c}$, and D. Paridaens ${ }^{a, d}$

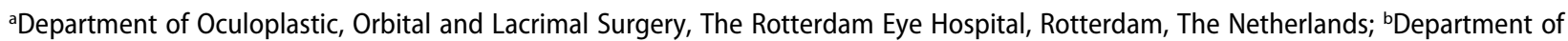 \\ Pathology, Section Ophthalmic Pathology, Erasmus MC, University Medical Center Rotterdam, The Netherlands; 'Department of Radiology and \\ Nuclear Medicine, Erasmus MC, University Medical Center Rotterdam, The Netherlands; ${ }^{d}$ Department of Ophthalmology, Orbital Service, \\ Erasmus MC, University Medical Center Rotterdam, The Netherlands
}

\begin{abstract}
Cellular angiofibroma is a benign mesenchymal tumor most commonly located in the distal genital tract of both men and women. Although extragenital locations have been reported rarely, this is the first report of cellular angiofibroma of the orbit. A 58-year-old man presented with a mass in the left superomedial orbit since 2 years. Magnetic resonance imaging showed a well-demarcated lesion with a homogeneous intermediate signal intensity on both T1- and T2-weighted images, homogeneous contrast enhancement and high signal intensity on diffusion-weighted images. Complete excision was performed through a medial upper eyelid crease incision. Histopathology showed a vascular CD34-positive and STAT6-negative spindle cell tumor with monoallelic loss of FOXO1, indicating cellular angiofibroma.
\end{abstract}

\section{ARTICLE HISTORY}

Received 15 May 2020

Accepted 9 June 2020

\section{KEYWORDS}

Cellular angiofibroma; mesenchymal tumor

\section{Introduction}

Cellular angiofibroma was first described as a benign mesenchymal tumor of the vulva by Nucci et al. ${ }^{1}$ Since then it has been reported most commonly in the distal genital tract of both men and women, although extragenital locations have been rarely reported as well. ${ }^{2-8}$ To date, however, no reports have been published on cellular angiofibroma of the orbit. In this report we describe clinical, radiological and histopathological characteristics of a case with cellular angiofibroma of the orbit.

\section{Case report}

A 58-year-old man was referred because of a swelling in the left superomedial orbit. Medical history included hypertension and gout. He had noticed the swelling two years earlier. Only little growth had been noted, but the lesion caused discomfort and was found to be cosmetically disturbing. Magnetic resonance imaging (MRI) was ordered by the referring ophthalmologist, and performed twice with a 6-month interval. MRI revealed a well-demarcated, non-calcified lesion with an intermediate signal intensity on both T1- and T2weighted images, with homogeneous enhancement after contrast administration and high signal intensity on diffusion-weighted images. There was no evidence of calcifications. The lesion was classified as a cavernous hemangioma, with no evident signs of growth. On clinical examination, a palpable mass was found in the left superomedial orbit and the eyelid was diffusely swollen (Figure 1). The vertical lid aperture measured $10 \mathrm{~mm}$ on the right side and $9 \mathrm{~mm}$ on the left side with a symmetric levator function of $17 \mathrm{~mm}$. There was no exophthalmos or non-axial displacement of the globe. Visual acuity was $20 / 20$ in both eyes and further ophthalmic examination was unremarkable. Re-evaluation of the MRI was performed by a radiologist specialized in orbital pathology, and concluded that the lesion did not fit the presumed diagnosis of cavernous hemangioma due to its location, shape and signal characteristics. Definite diagnosis was unsure, but due to the restricted diffusion orbital lymphoma was suggested (Figure 2). Surgical resection of the lesion was performed under general anesthesia through a medial upper lid crease incision. Intraoperatively it showed to be a smooth tumor that could be resected completely without difficulties to acquire hemostasis (Figure 3A). Post-operative recovery was uneventful (Figure 3B). Histopathology (Figure 4) was reviewed by a panel of pathologists specialized in ophthalmic and soft tissue pathology and revealed a vascular, not atypical, CD34-positive and STAT6negative spindle cell tumor which, based on monoallelic loss of FOXO1 by fluorescence in situ hybridization (FISH), could be best classified as a cellular angiofibroma.

CONTACT G.J. Hötte g.hotte@oogziekenhuis.nl Department of Oculoplastic, Orbital and Lacrimal Surgery, The Rotterdam Eye Hospital, 3000 LM Rotterdam, The Netherlands 


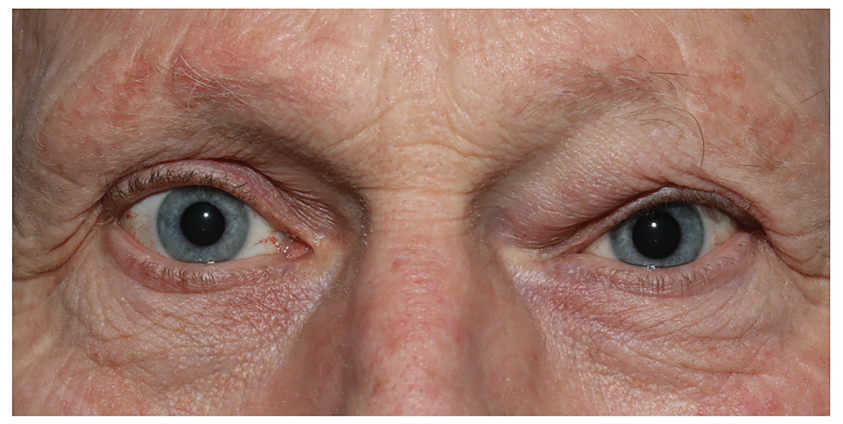

Figure 1. Presentation. Ophthalmic examination showed a mass located in the left superomedial orbit with diffuse swelling of the eyelid.

\section{Discussion}

Cellular angiofibroma is a benign mesenchymal tumor most commonly located in the distal genital tract of both men (inguino-scrotal region) and women (vulvo-vaginal region). ${ }^{2,3}$ Extragenital locations have been reported rarely and include the hypopharynx, nasopharynx, oral mucosa, pelvis, hypochondrium, retroperitoneal space, breasts, chest and extremities. ${ }^{3-8}$ In this report, we present the first case of cellular angiofibroma located in the orbit.

As in the more common locations, it presented as a slowly growing mass, causing only mild discomfort.
The MRI characteristics of cellular angiofibroma vary amongst reports. ${ }^{9-11}$ As in our case, T1-weighted images are mostly found to be of intermediate signal intensity, while T2-weighted images can show either low, intermediate or high signal intensity. Differences in these characteristics may depend on variations in the tumor's histological background such as the amount of spindle cells, myxoid and collagenous stroma and fat. Similar histological variations may also effect contrast enhancement of the tumor: the more and more evenly vascularized, the more intensely and homogeneously enhanced by gadolinium contrast. $^{9,10}$ Interestingly, Ntorkou et al found no areas of restricted diffusion, while in our case high signal was noted on DWI. ${ }^{9}$

Histologically, we found a vascular CD34-positive spindle cell tumor with monoallelic loss of FOXO1. The tumor was negative for STAT6 and therefore did not fit the diagnosis of giant cell angiofibroma/solitary fibrous tumor. Indeed, cellular angiofibroma is typically characterized as a well circumscribed tumor composed of bland spindle cells in an edematous to fibrous stroma with hypo- and hypercellular areas and numerous small- to medium-sized thick-walled vessels. $^{2,3}$ Intralesional fat is found in some but not all cellular angiofibromas. Some may show mitotic activity but there is typically no necrosis. ${ }^{2,3}$ Looking
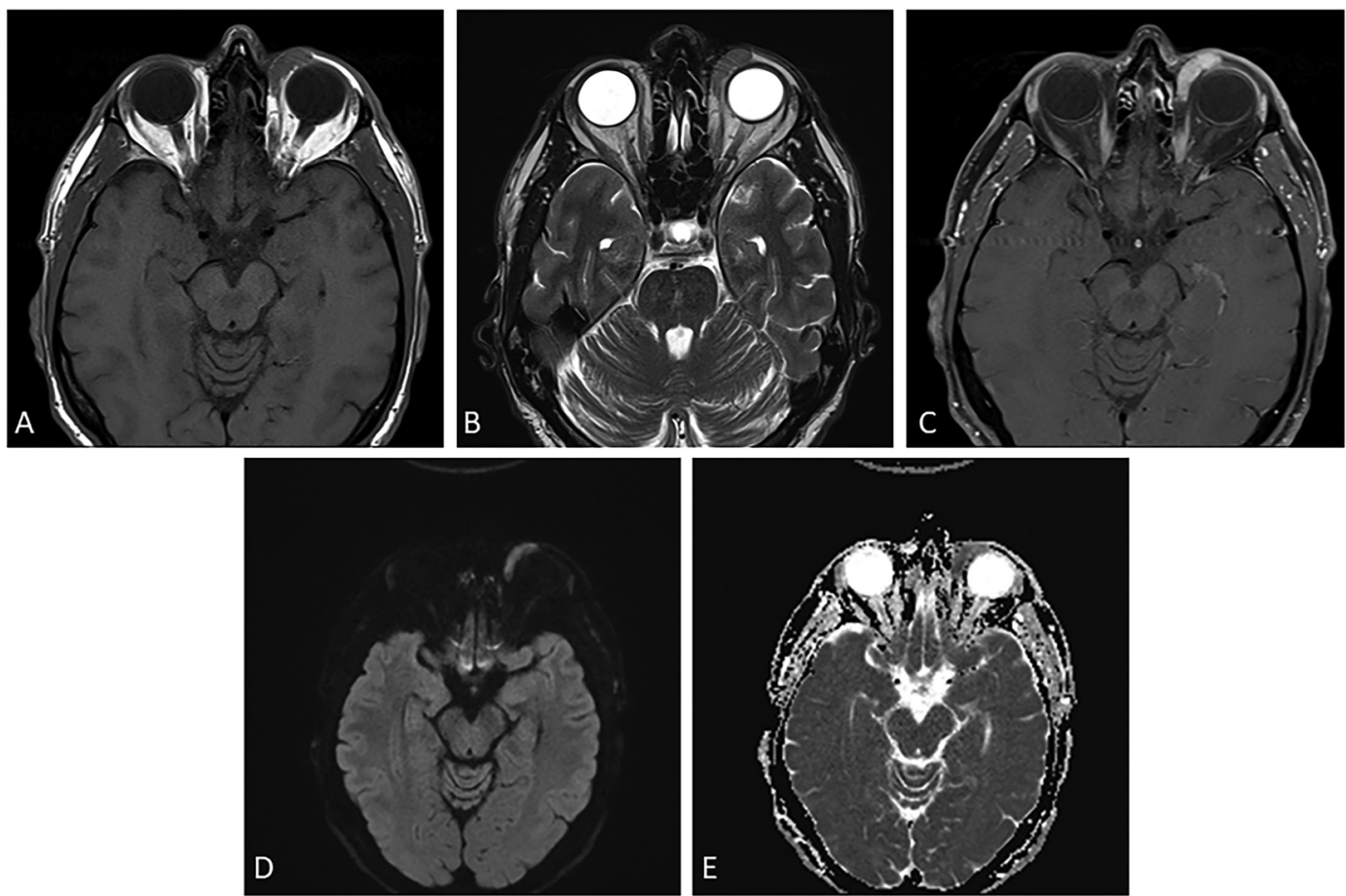

Figure 2. Magnetic resonance imaging. A lobulated mass is appreciated anteriorly within the left superomedial orbit, extending both pre- and postseptally, molding around the globe but not infiltrating surrounding structures. The lesion has homogeneous intermediate signal intensity on both T1- (A) and T2-weighted (B) images, shows homogeneous enhancement after contrast administration (C), and high signal on the diffusion-weighted image (D) with diffusion restriction on the apparent diffusion coefficient (ADC) map (E). 

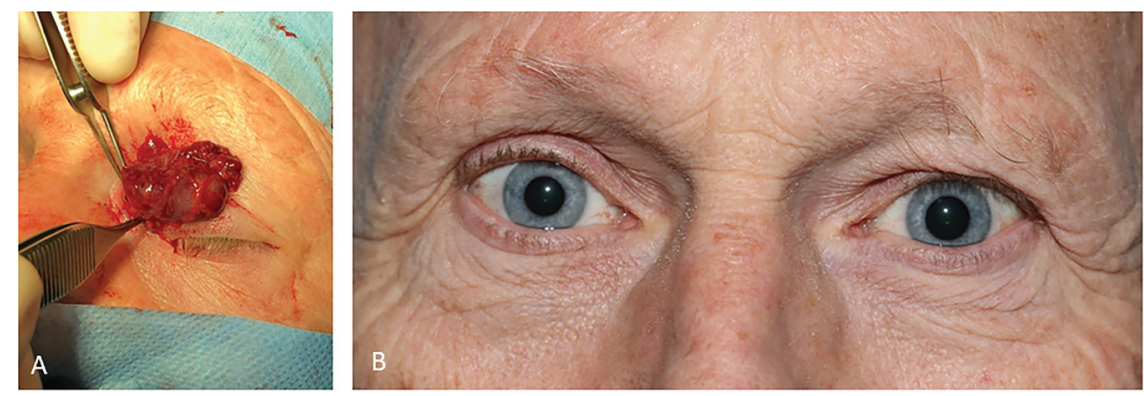

Figure 3. Intra-operative appearance and post-operative result. (A) Complete surgical excision of the lesion was performed through a medial upper eyelid crease incision. The lesion did not appear to infiltrate surrounding tissues. (B) Post-operative recovery was uneventful.

at immunohistochemical profiles, most tumors are CD34 positive and negative for S-100 protein. Variable staining profiles are found for SMA, EMA and desmin. Interestingly, they may also express estrogen and progesterone receptors. ${ }^{2,3}$ FISH shows monoallelic loss of FOXO1 in cellular angiofibroma, spindle cell lipoma and mammary-type myofibroblastoma, but not in giant cell angiofibroma/solitary fibrous tumor. ${ }^{3}$ The diagnoses of spindle cell lipoma and mammary-type myofibroblastoma were rejected in the current case based on histopathology. Although reports on atypia or sarcomatous transformation have been made, no such signs were found in our patient. $^{12}$

Treatment of cellular angiofibroma consists of simple excision, which even in case of atypia or sarcomatous transformation seems to be adequate. ${ }^{3}$ In line with these reports, our patient has not shown
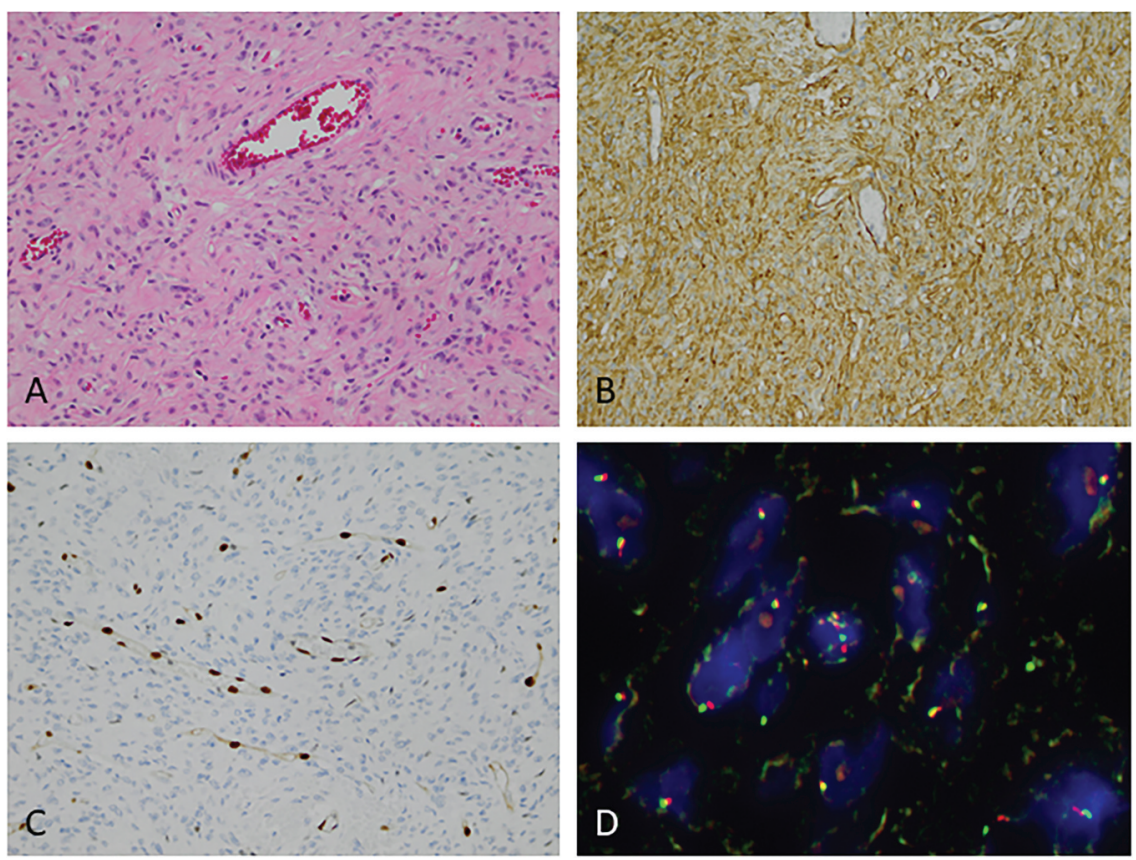

Figure 4. Histopathology, immunohistochemistry and FISH. (A) Histopathology reveals both fatty and connective tissue with a cellular and vascular proliferation of spindle cells with little eosinophilic cytoplasm and oval nuclei with a fine chromatin pattern and prominent or sometimes double nucleoli. Nuclei are only slightly polymorphic. Diffusely scattered are vascular spaces covered with endothelium that is flattened and not atypical. There are no mitotic figures or necrosis. (Displayed: 200x Hematotoxylin and Eosin staining)(B) Immunohistochemistry was diffusely positive for CD34, cytoplasmatic WT-1 and factor XIIla. S100 was questionably positive. Stainings were negative for STAT6, EMA, SMA, GLUT1, CD31, HMB45, SOX10, Melan A, ERG, desmin and pankeratin. (Displayed: 200x CD34 staining)(C) Only luminal endothelium of the vascular spaces stains positive for the endothelial marker ERG, the spindle cells are negative (Displayed: 200x ERG staining)(D) Fluorescence in situ hybridization (FISH) shows mono allelic loss of FOXO1 using a split apart probe. Single closely related green and red signals can be observed for each nucleus indicating complete loss of one gene and a normal configuration of the remaining signal. 
any signs of recurrence during 11 months of followup.

In conclusion, cellular angiofibroma is a benign mesenchymal tumor that deserves a place in the differential diagnosis of solid tumors in the orbit. Clinical and histopathological characteristics resemble those of cellular angiofibroma found elsewhere in the body.

\section{Disclosure of interest}

The authors report no conflicts of interest.

\section{References}

1. Nucci MR, Granter SR, Fletcher CD. Cellular angiofibroma: a benign neoplasm distinct from angiomyofibroblastoma and spindle cell lipoma. Am J Surg Pathol. 1997;21(6):636-644. doi:10.1097/00000478-19970600000002.

2. Iwasa Y, Fletcher CD. Cellular angiofibroma: clinicopathologic and immunohistochemical analysis of 51 cases. Am J Surg Pathol. 2004;28(11):1426-1435. doi:10.1097/01.pas.0000138002.46650.95.

3. Mandato VD, Santagni S, Cavazza A, Aguzzoli L, Abrate M, La Sala GB. Cellular angiofibroma in women: a review of the literature. Diagn Pathol. 2015;10:114. doi:10.1186/s13000-015-0361-6.

4. Liu Y, Xu Y, Wang Q, Chen Q. Cellular angiofibroma in the hypopharynx: A case report. Medicine (Baltimore). 2019;98(50):e18385. doi:10.1097/MD.00000000000 18385.
5. Erdur ZB, Yener HM, Yilmaz M, Karaaltin AB, Inan HC, Alaskarov E, et al. Cellular Angiofibroma of the Nasopharynx. J Craniofac Surg. 2017;28(8):e720e722. doi:10.1097/SCS.0000000000003845.

6. Eversole LR. Cellular angiofibroma of oral mucosa: report of two cases. Head Neck Pathol. 2009;3 (2):136-139. doi:10.1007/s12105-009-0112-7.

7. Perrin C, Cannata GE, Pedeutour F, DadoneMontaudie B, Ambrosetti D. Cellular angiofibroma: case report of a unique subungual presentation. Acta Derm Venereol. 2019;99(10):915-916. doi:10.2340/ 00015555-3152.

8. Omori Y, Saeki H, Ito K, Umezawa Y, Ishiji T, Ota A, et al. Extragenital subcutaneous cellular angiofibroma of the elbow. J Eur Acad Dermatol Venereol. 2014;28 (6):828-830. doi:10.1111/jdv.12312.

9. Ntorkou AA, Tsili AC, Giannakis D, Batistatou A, Stavrou S, Sofikitis N, et al. Magnetic resonance imaging findings of cellular angiofibroma of the tunica vaginalis of the testis: a case report. J Med Case Rep. 2016;10:71. doi:10.1186/s13256-016-0861-3.

10. Koo PJ, Goykhman I, Lembert L, Nunes LW. MRI features of cellular angiomyofibroma with pathologic correlation. J Magn Reson Imaging. 2009;29 (5):1195-1198. doi:10.1002/jmri.21747.

11. Miyajima K, Hasegawa S, Oda Y, Toyoshima S, Tsuneyoshi M, Motooka M, et al. Angiomyofibroblastoma-like tumor (cellular angiofibroma) in the male inguinal region. Radiat Med. 2007;25(4):173-177. doi:10.1007/s11604-006-0114-2.

12. Chen E, Fletcher CD. Cellular angiofibroma with atypia or sarcomatous transformation: clinicopathologic analysis of 13 cases. Am J Surg Pathol. 2010;34(5):707-714. doi:10.1097/PAS.0b013e3181d74bdb. 